table, time is allowed for the blocks to be pushed home before the table top is lowered upon them, so that the blocks are relieved from the weight whilst they are being moved. Fig. 2 is a plan of this turntable, showing the position of the long lever $\mathrm{B}, \mathrm{B}$, and the horizontal rollers $G$, $G$, that work around the centre pillar $A$. At the end of the lever $L, a$ weight is fixed to balance the weight of the table top to within a few cwts.; the balance weight not being made heavy enough to raise the table top without the exertion of a slight pressure on the handle $\mathrm{m}$. Other modifications of this improved table might be described, but as the principle in them all is the same, viz., to carry the weight on the centre pin when the table is being used, and upon the circumierence when not in use, it is not necessary in the present paper to do so.

'This mode of construction insures a solid turntable, one very easy to turn, and a very durable one; the working parts do not get deteriorated by the passing of trains, and are so placed that dirt cannot collect upon them; the extent of bearing surface at the circumference is greatly increased, and prevented from becoming indented as in roller tables; a smooth and easy motion is obtained by turning entirely upon the centre, as no inequality of bearing surface has to be overcome; also, less oil is consumed for the centre bearing than for rollers, and the working parts are more easily oiled. In roller tables an increased load increases greatly the resistance to turning, and after some years' wear they work more heavily; but in centre bearing tables much less difference is experienced. Also, the cost of foundation, instead of being more, is rather less than that required for roller turntables with a live ring and rollers, as a continuous ring of masonry is not required round the circumference, but only six or eight blocks of stone, one under each arm of the centre pillar, in addition to the centre stone, which is required in both descriptions of turntables.

\title{
Annual Report of the Engineer of the Philadelphia Gas Works.
}

TO TIE TRUSTEES OF THE PIILADELPHA GAS WORKS:

Gentlemen:-The Engineer respectfully presents to the 'Trustees of the Philadelphia Gas Works his Eighteenth Annual Report, detailing the operations of the Works for the year 1853.

In the quantity of Gas manufactured, there is an increase of thirtythree million cubic feet.

Considerable difficulty has been experienced in obtaining a sufficient supply of coals, in consequence of which it has been found necessary to buy varieties of inferior productiveness at high prices, whereby the yield of gas to the pound of coal will be diminished, and its cost much increased. In other respects the results obtained are as favorable as usual.

'There has been manufactured during the year, two hundred and fortynine million four hundred and twenty-seven thousand cubic feet of gas; making an aggregate production from the works of sixteen hundred and sixty-four million three hundred and forty-four thousand cubic feet. 
The product for the year has been distributed in the following proportions to the different municipal sections, supplied from our Works.

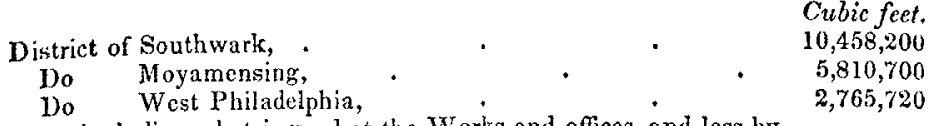

City, including what is used at the Works and offices, and loss by leakage, and opening of mains for connexions and service pipes, $230,392,380$

$249,427,090$

'The maximum product of gas in twenty-four hours, was one million one hundred and thirty-seven thousand cubic feet.

The maximum consunption, one million three hundred and eighteen thousand feet.

For the manufacture of gas, the materials used in the year, are as shown in the following statement:

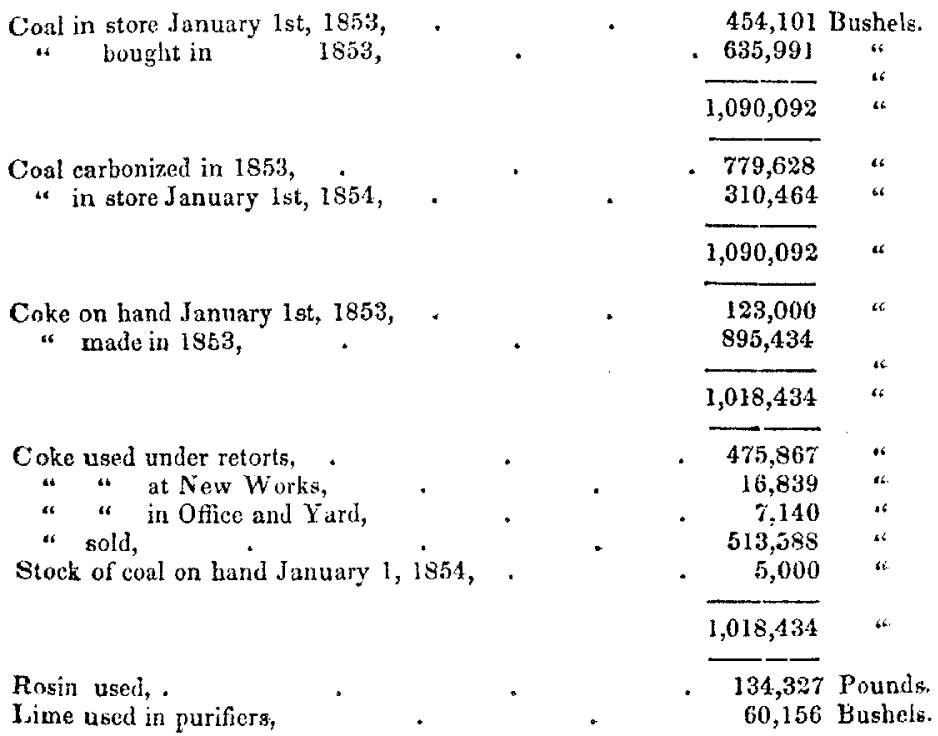

In the department of distribution, the additions to the service pipes and meters, have again surpassed those of any former year, and the increase in number of lights is also greater than has been experienced. The main pipes laid in streets have been as follows: two inch pipes, seven thousand one hundred and fifty-two feet; three inch, three thousand seven hundred and forty-four feet; four inch, three thousand seven hundred and eighty feet; six inch, four hundred and fourteen feet; sixteen inch, seven hundred and twenty feet; twenty inch, seven thousand two hundred and fifty-seven feet; total, twenty-three thousand and sixtyseven feet. The entire length of street gas mains is now six hundred and twenty-seven thousand two bundred and thirty-three feet, or ont hundred and eighteen and three-quarter miles.

There have been one thousand three hundred and sixty-four service 
pipes laid in new places, and the same number of new meters set; which; added to those before in use, make an aggregate of thirteen thousand and seventy-four services and meters.

Applications for gas have been registered to the number of three thousand two hundred and eighty, and the removals, and discontinu ances are one thousand nine hundred and fifty-four; leaving one thousand three hundred and twenty-six as the increase of consumers, and making the whole number of consumers at this time, twelve thousand nine hun* dred and eighty-nine. The lights added are twenty-five thousand four hundred and thirty-two private, and eighty-eight public; also, twentythree in Independence Square. The Districts of Sonthwark and Moyamensing, and West Philadelphia, report fifteen thousand six hundred and twenty-nine prirate, and four hundred and eighty-five public lights; which make a grand total of two hundred thousand eight hundred and forty-five supplied from our Works.

In one of the Western Public Squares, main pipes have been laid down by the direction of the Committee on City Property, but the gas. has not yet been introduced.

By reason of the great increase of street mains and service pipes and meters the expenditures in this department have outrun the provisions keretofore made for it, to an extent that makes some further authoritative action a matter of imperative necessity. When in the year 1844 the Contingent Fund was devoted to the purpose of defraying the cost of the extensions of distribution, the number of services and meters required to meet the demands of new customers had averaged in the previous three or four years not quite three hundred and fifty per annum, and therefore the sum of thirty thousand dollars a year, to which the Contingent Fund was restricted, was deemed sufficient for this object. Since that period the annual applications for gas have become much more numerous, and particularly so since the recent large extension of the main pipes into all quarters of the City for the purpose of affording to every section the advantages of street lighting. 'The growth in this respect has exceeded all anticipations formed in regard to it, so that instead of the average of three hundred and fifty a year, on which the limitation of the Contingent Fund was based, the new services and meters furnished have increased to the large number of one thousand three hundred and sixty-four in the last year, and bave averaged nearly one thousand two hundred and eighty the last three years. As a necessary consequence, the expenditures of this department have grown from the original estimate of thirty thousand dollars a year to over serenty-five thousand; and thus not only absorbed the whole of its own proper Fund, but have also encroached largely upon the resources designed for the enlargement of the Works and for Working Capital. All that can be derived from these sources is now exhausted, and the increase of street mains and service pipes and meters must therefore cease until funds are provided for their cost.

At the new Works in Passyunk, the principal structures are all roofed in and nearly completed; and as much progress has been made in fitting up the apparatus and its connexions as circumstances allowed. Much delay has arisen in the prosecution of this work from the unusual scarcity of 
skilled laborers; and the difficulty from this cause was enhanced by the want of suitable dwellings for the accommodation of the workmen; in consequence of which it has been impossible to keep the desired force on the work; for in a season of unusually active employment, many work. men refuse to engage at a place so far distant from their residence; and it was found that skilful mechanics could be kept steadily employed, only by providing them with means of conveyance to and from their work, whereby much expense has been imposed on the Contractors and on the Gas Works.

The same difficulty of accommodations made it expedient to postipone the cominencement of Gas Nitking Operations to the latest possible period: for the accomplishment of which it has been necessary to kee' the Apparatus at the old Works in the highest state of efficiency attainable by the most virilant daily inspection, and the prompt renewal of the parts exposed to destructive agencies, without waiting for the degree of dilapidation ordinarily admissible. By these means the supply of gas has been thus far maintained without recourse to the New Works, and it is believed it may be carried through the present winter unless some unforeseen disaster should occur to diminish materially their effective condition.

Should the question of the erection of dwelling-houses for the workmen be left in its present unsettled state, in which no authority is granted to the Trustees and no incentive is oflered to individuals to undertake their construction, very serious inconvenience and much useless expense will be the probable result.

$$
\text { Very respectilly submitted, by }
$$

JoHn C. Cresson, Engineer.

Philadelphia Gas Works, January 1sth, 1854.

\section{AMERICAN PATEN'TS.}

List of Americun Patents which issued from February 7th, 1854, to Februany 28 th, 1851, (inclusive,) with Exemplifications by Cuanes M. Keulen, late Citicf Examiner of Patents in the U. S. l'atent office.

\section{FEBRUARY 7.}

1. For Impronements in Rotury Engines; Ebenezer Barrows, City of New York; patented in England, July 3, 1851.

Claim.- "I do not claim the sliding pistons, nor an abutment or stop in the steam channel or passage around the interior of the cylinder, irrespective of the manner in which they are arranged, and in which they operate; but I claim, 1st, the revolving stcam wheel, having projecting rims or flanches, revolving within the interior of a stationary cylinder, in which there are two or more fixed alutments or stops, which fit steam-tight, so as to close and divide the annular space between the cylinder and wheel, into two or more steam chambers; the said steam wheel having four or more pistons whose operation is controlled by a stationary curved groove or way in each cylimder head, so as to be alternately acted upon by the steam in the cylinder, and down within the wheel, so as to pass and clcar the abutments or stops, substantially in the manner shown. $2 \mathrm{~d}$, The six way cocks or steam heads, having each a steam passnge leacling to its plug seat, two steam passages leading from the plug seat to opposite chambers of the cylinder, two exhaust
passages leading from opposite chambers of the cylinder back to the plug seat, and one 